\title{
Manejo empresarial de un bosque post huracán en la RAAN
}

\author{
Javier López \\ Maderas Preciosas Indígenas Industriales de Nicaragua, S.A. (MAPIINICSA)
}

Quiero agradecer al comité organizador por habernos brindado la oportunidad para presentar un poco sobre los avances en cuanto al manejo del bosque que se realiza en la finca Rosita, localizada en la comunidad El Black.

\section{Plan de aprovechamiento forestal de la finca}

La Empresa MAPINICSA inicia sus operaciones forestales a partir del año 2008, aquí en la Región Autónoma del Atlántico Norte. Para eso se conformó esta empresa denominada Madera Preciosa Indígena Industriales de Nicaragua S.A. Queremos compartir con ustedes cuál es el manejo del bosque que se está haciendo en la finca, principalmente lo que es este proceso de extracción controlada y el establecimiento de una industria forestal dentro de la finca.

El producto de primera transformación es transportado hacia la planta industrial en Managua y allí es donde se hace todo el proceso de industrialización, es decir, la segunda y la tercera transformación. Luego, el producto va directamente hacia el mercado extranjero.

La empresa tiene un plan de aprovechamiento forestal en una área de 3,244 ha, que se encuentra localizada en la comunidad El Black, municipio de Rosita. El periodo de duración de este plan de acción forestal es de cinco años. Además de eso se tiene un permiso ambiental sobre la instalación y operación de aserríos estacionarios, o sea, en la finca se hace el proceso de extracción controlada y toda la madera que es extraída de la zona huracanada es llevada al patio principal y allí se procesa en los aserríos portátiles que están en la finca.

Para llegar a esta finca se utiliza la carretera que viene de Puerto Cabezas, y en el empalme de Wasminona se tuerce unos $18 \mathrm{~km}$ hacia el aserrío donde se tiene el campamento. En este campamento se encuentra todo el personal que se encuentra en la empresa, aproximadamente cien trabajadores. Cuando iniciamos operaciones hace un año éramos unos 130 trabajadores. De estos trabajadores, el 80 por ciento son trabajadores de la región, y un 20 por ciento viene del lado del Pacífico.

\section{Metodología del inventario forestal}

A inicios de este año se ejecutó un inventario forestal. Se hizo un inventario sistemático con parcelas rectangulares de $20 \mathrm{~m}$ de ancho por $125 \mathrm{~m}$ de largo. El área de la parcela era de 1.25 ha. Seguimos la metodología de la FAO para inventarios. La intensidad de muestreo fue de $1.30 \%$. Cada línea de inventario estaba separada $500 \mathrm{~m}$ entre sí, y entre parcela y parcela había una distancia de $500 \mathrm{~m}$. En total, en toda la finca se levantaron 171 parcelas de aproximadamente 1.25 ha.

\section{Variables de árboles en pie y caídos}

Las variables que se usaron tanto para los árboles en pie como para los caídos fueron: tipo de especie, DAP, altura comercial y total, y calidad del fuste. En el caso de los árboles caídos se determinó: la especie, el DAP mayor y el menor, la longitud de la troza y la calidad de la misma. Esto lo hicimos con la finalidad de conocer el potencial productivo que existe en la finca MAPINICSA.

\section{Aprovechamiento controlado}

Una vez que se hizo el inventario se procedió al proceso de aprovechamiento controlado. Se planificó lo que fue la construcción de la red vial en cuanto a camino primario, camino secundario y las trochas. Así mismo se hicieron las construcciones de puentes, filtros y patios de acopio, tanto a nivel de montaña como de patio principal.

Después de realizadas todas estas actividades de la red vial, se procedió a ejecutar lo que era el aprovechamiento: troceo y arrastre de árboles caídos a patios de montañas, el enguillado de madera en rollo y el transporte de madera en rollo al patio principal.

Luego de finalizadas las actividades de la red vial se procedió a realizar lo que era propiamente el aprovechamiento. Se 
hizo una capacitación a todo el personal, principalmente a los motosierristas que iban a estar operando cada una de esas maquinas. Se hizo el troceo y los arrastre de arboles caídos a los patios de montaña. Para eso se utilizaron tractores con cables de arrastre.

Cuando toda esta madera llega a los patios de montaña, inmediatamente se procede a alinear la madera en royo en cada uno de los patios de montaña. Para esto se utilizan las guías que INAFOR tiene definida para la madera en royo. Toda vez que la madera está enguillada se procede al transporte al patio principal con toda la documentación debidamente llena y que ha establecido INAFOR en su guía.

\section{Resultados}

El cuadro muestra los resultados obtenidos del inventario

\begin{tabular}{|c|c|c|c|c|}
\hline ESPECIES & CANTIDAD & $\%$ & $\begin{array}{c}\text { VOLUMEN } \\
\text { m3/ha }\end{array}$ & $\begin{array}{c}\text { DENSIDAD } \\
\text { Arb/ha }\end{array}$ \\
\hline Todas & 67 & & & \\
\hline Comerciales & 15 & 22.00 & 34.05 & 29.12 \\
\hline Potenciales & 12 & 18.00 & 10.61 & 18.64 \\
\hline Conservación & 40 & 60.00 & 58.40 & 68.98 \\
\hline
\end{tabular}

\section{Especies encontradas}

Se identificaron suficientes especies de árboles de los cuales 15 son comerciales, 12 potencialmente comerciales y 40 identificadas como de conservación. Puede observarse que las especies comerciales y potenciales representan el $38 \%$ y las de conservación el 60\%. Determinamos también cuánto es el volumen de las especies comerciales de estas 15 , lo que nos daba un valor de $34 \mathrm{~m}^{3}$ por ha, con una densidad arbórea de potenciales y de conservación que fueron identificado de 16 y $58 \mathrm{~m}^{3}$ por ha.

\section{Especies comerciales}

Caoba, cedro macho, ceiba, come negro, cortez, jenízaro, guanacaste, guapinol, guayabo, laurel, leche maría, nancitón, terciopelo.

\section{Especies potenciales}

Acetuno, areno, canelo, capirote, cebo, kerosén, níspero, ojoche, plomo quebracho, quita calzón y rosita.

\section{Especies de conservación}

Aguacate, ajo, barazón, bimbayan, botija, cachito, capulín, chaperno, cola de pava, concha de cangrejo, guaba, guácimo, guina, huesito, jovo, lagarto, leche vaca, manga larga, muñeco, palo de agua.

Luego, en el patio principal, una vez que la trozas llegan y se hace el ingreso de la madera en rollo se hace una verificación por especie y se dimensiona cada una de las trozas, se hace un proceso de saneo y el apilamiento

\section{Construcción de la red vial}

Como expresé al inicio, se hizo la construcción de red vial de $18 \mathrm{~km}$ de camino (recarpeteo y revestimiento), que va de la comunidad Wasminona a la finca MAPIINICSA. Este es uno de los aportes sociales que ha hecho la empresa para mejorar la penetración del camino de Wasminona hacia la finca.

A nivel de la finca se hizo un camino primario dentro de la finca, de aproximadamente $18 \mathrm{~km}$. En este mismo camino se hizo el cuneteado de $12 \mathrm{~km}$ a ambos lados del camino; se construyeron caminos secundarios y trocha, aproximadamente $40 \mathrm{~km}$, considerando siempre, donde se hicieron las líneas de inventario aprovechar para construir los caminos secundarios y se tomaron las referencias que tiene INAFOR en cuanto a las dimensiones de los caminos de extracción. A nivel de caminos primarios se han construido cinco puentes, 10 alcantarillas fluviales y 37 filtros.

Así mismo hay un patio de acopio principal y 30 patios de montañas, que están distribuidos en todas las áreas en donde se ha realizado el proceso de aprovechamiento.

Una de las acciones principales que la empresa está haciendo en el ámbito del bosque, a nivel de todo el 
polígono, es decir, en toda la circunferencia de la finca, fue la realización de una ronda cortafuego de cinco metros de ancho. Hay una brigada contra incendio conformada por los trabajadores de la finca.

Uno de los procesos fundamentales que la empresa ha impulsado y desarrollado en este período fue certificar la finca en cuanto al estándar FSC (SW-CW/FM-003314) de madera controlada. El otro estándar que tiene la empresa, que se constituyó aproximadamente hace diez meses fue el estándar FSC (SW-COC-001387) de cadena de custodia.

\section{El proceso de la madera controlada}

En el caso de la madera controlada, todo el proceso inicia desde la madera que está en el bote hacia el patio de acopio, luego todo el proceso que se hace en la industria, hasta que sale en los camiones. Aquí concluye el proceso de madera controlada.

Una vez que llega este camión a la planta industrial en Managua, entra a funcionar el estándar de cadena de custodia. Este es el proceso que lleva la madera controlada. Hace poco tuvimos una auditoría de parte de una compañía radicada en Guatemala, sobre el certificado de ...Wood.

El proceso de industria en la finca inicia desde cuando la madera en rollo llega al patio principal, luego pasa al área de troceo donde se cortan las trozas. Posteriormente pasa al área de apilamiento, después a la alimentación del aserrío (en la finca existen dos aserríos portátiles y dos estacionarios), luego que la madera es aserrada se apila, pasa el proceso de canteo, despuntado, selección del producto, clasificación y se hace el proceso de carga y transporte de la madera aserrada.

Un aporte importante que hace la empresa aquí es que toda la madera que sale aserrada, de primera transformación va enbultada y controlada con el número de piezas que se está transportando y que aparece en la guía de transporte. Todo este proceso facilita, una vez que esa rastra llega a la industria, pasar la madera al desmontado y al área de secado donde cada uno de los seis hornos puede secar unos 30 mil pies tablares. Aquí concluye lo que es el proceso de madera controlada. De esta forma podemos decir que la empresa está siendo un proceso de extracción de madera controlada.

\section{Plan de reforestación}

Otro aspecto importante que tiene la empresa es un plan de reforestación. Hasta el momento se han establecido 50 ha, con 30 mil plantas de caoba del Atlántico y granadillo. Existe también un vivero y hay unas tres mil plantas para reforestar la vega de las fuentes de agua, con cedro real y leche maría.

Un aspecto importante es la plantación que se ha hecho ahorita de reforestación -un enriquecimiento más bienal área de bosque. Sobre la línea de inventario se han establecido las especies de caoba del atlántico y el granadillo. Esto tiene unos cuatro meses establecidos. Actualmente tienen una altura de $1.5 \mathrm{~m}$, con apenas un año de establecido. La empresa ha decidido impulsar un plan de reforestación más intensivo, con la intención de enriquecer toda esa área de bosque. Para esto ya se hicieron los contactos con una empresa que vende semillas en Bonanza, para hacer reforestación en las áreas aprovechadas. Existen ciertas áreas de la finca en donde verdaderamente hay escasez de árboles. Allí es donde se intensificará el proceso de plantación.

\section{Estación biológica BTH fundación naturaleza}

Un aspecto relevante es que se han definido dentro de las finca 300 ha para establecer una estación biológica con la fundación Naturaleza que dirige el Dr. Incer Barquero. Ya se firmó el convenio y se dieron ya las primeras pláticas al respecto. Posiblemente venga esta semana un personal de la universidad de Texas, para conocer el área.

Dentro de esas 300ha se han definido cuatro líneas de investigación: 1) Cual es la estructura de la regeneración natural. En este sentido hay que señalar que esas trescientas ha están intactas, tal y cómo las dejó el huracán. 2) Cuál es el grado de perturbación causado por la intervención antrópica, 3) la identificación de las especies no maderables y 4) el establecimiento de parcelas de muestreo. En los próximos quince días se van a comenzar a establecer dichas parcelas las cuales cada una serán de una ha y éstas van a estar tanto dentro de las 300 ha como fuera de la periferia de la finca, para conocer el estado actual en que se encuentra el bosque remanente.

\section{Impacto social}

Cuál es el impacto social que la empresa ha generado durante este año y medio de ejecución de la explotación. 
Primero hay que señalar que cuenta con 100 trabajadores permanentes, distribuidos de la siguiente manera:

\begin{tabular}{|l|c|}
\hline DESCRIPCION & CANTIDAD \\
\hline Vivero y Plantación & 11 \\
\hline Aprovechamiento & 20 \\
\hline Industria forestal & 54 \\
\hline Administración & 15 \\
\hline TOTAL & 100 \\
\hline
\end{tabular}

Como pueden ver, una de las fortalezas de la empresa es el impacto en cuanto a la generación de empleo. Estos trabajadores tienen contratos, están afiliados al INSS (uno de los requisitos que exigió la certificación del organismo que dio el préstamo a la empresa). Estos trabajadores también reciben sus prestaciones sociales, alimentación, equipos de seguridad laboral y algunos duermen en la finca.

\section{Proyecciones futuras}

\section{Área social}

Hicimos un trabajo con las comunidades que habitan en el entorno de la empresa, con el objetivo de apoyar la parte social. Existen aproximadamente 18 comunidades que habitan alrededor de la finca, y luego de la consulta sobre sus necesidades sociales, la empresa decidió comprometerse en:

$>$ Construcción de un Centro de Salud, con atención materna, en la comunidad El Black, por ser ésta la más accesible de las 17 comunidades.

> Apoyar la construcción de dos escuelas (comunidad El Rosario y Waspado)

\section{Manejo del bosque}

Establecimiento y Manejo Plantaciones.

Medidas de Mitigación, principalmente en aquellas actividades de post aprovechamiento (cierre de las trochas, cómo quedan las condiciones de los claros, cómo se pueden enriquecer).

Actualización del PAF, incorporando todos estos proceso de trabajo en la empresa.

Esta es mi pequeña participación y estoy muy agradecido por habernos invitado a participar en este foro. 